\title{
Anatomical structures involved in non-human vocalization
}

\author{
Alban Gebler \\ Roland Frey \\ Leibniz Institute for Zoo and Wildlife Research (IZW), Berlin, Germany
}

In order to understand the functional morphology of the human voice producing system, we are in need of data on the vocal tract anatomy of other mammalian species. The larynges and vocal tracts of four species of Artiodactyla were investigated in combination with acoustic analyses of their respective calls. Different evolutionary specializations of laryngeal characters may lead to similar effects on sound production. In the investigated species, such specializations are: the elongation and mass increase of the vocal folds, the volume increase of the laryngeal vestibulum by an enlarged thyroid cartilage and the formation of laryngeal ventricles. Both the elongation of the vocal folds and the increase of the oscillating masses lower the fundamental frequency. The influence of an increased volume of the laryngeal vestibulum on sound production remains unclear. The anatomical and acoustic results are presented together with considerations about the habitats and the mating systems of the respective species.

\section{Introduction}

Although the human ability for speech is the most prominent example, acoustic communication has also evolved in many other species. Apart from intellectual requirements, the anatomy of the human larynx and vocal tract seems to be highly adapted to produce a huge variety of sounds. But what about adaptations in other vocalizing species?

The debate on a lowered larynx as a precondition for modern human speech (Lieberman \& Crelin 1971) is an example of how the knowledge of animal vocal tract morphology influences the understanding of the evolution of the human vocal apparatus. A constant or temporary lowered larynx position has been documented in an increasing number of species. Thus, it becomes more and more implausible that larynx descent itself can be used as a criterion for the 
ability to articulated speech (cf. Fitch \& Reby 2001, Boe et al. 2002, Nishimura et al. 2003).

In contrast to human speech, the acoustic communication system of many animal species comprises only few more or less fixed call types. The acoustic parameters of these calls, e.g. the amplitude of sound pressure, the fundamental frequency and the spectral distribution of energy within the frequency range, are adapted to the acoustical properties of the species' habitat. Additionally, the emission of specific calls as one component of mating behaviour can be crucial for the mating success in many animal species. Despite the basic similarity of the vocal apparatus in mammals, the great diversity of habitats and social systems has led to the evolution of an accordingly great variety of vocal tract specializations. Unfortunately, our knowledge of the head and neck anatomy of almost all wild living species is sparse. In particular, details of the vocal tract morphology are still lacking in many species.
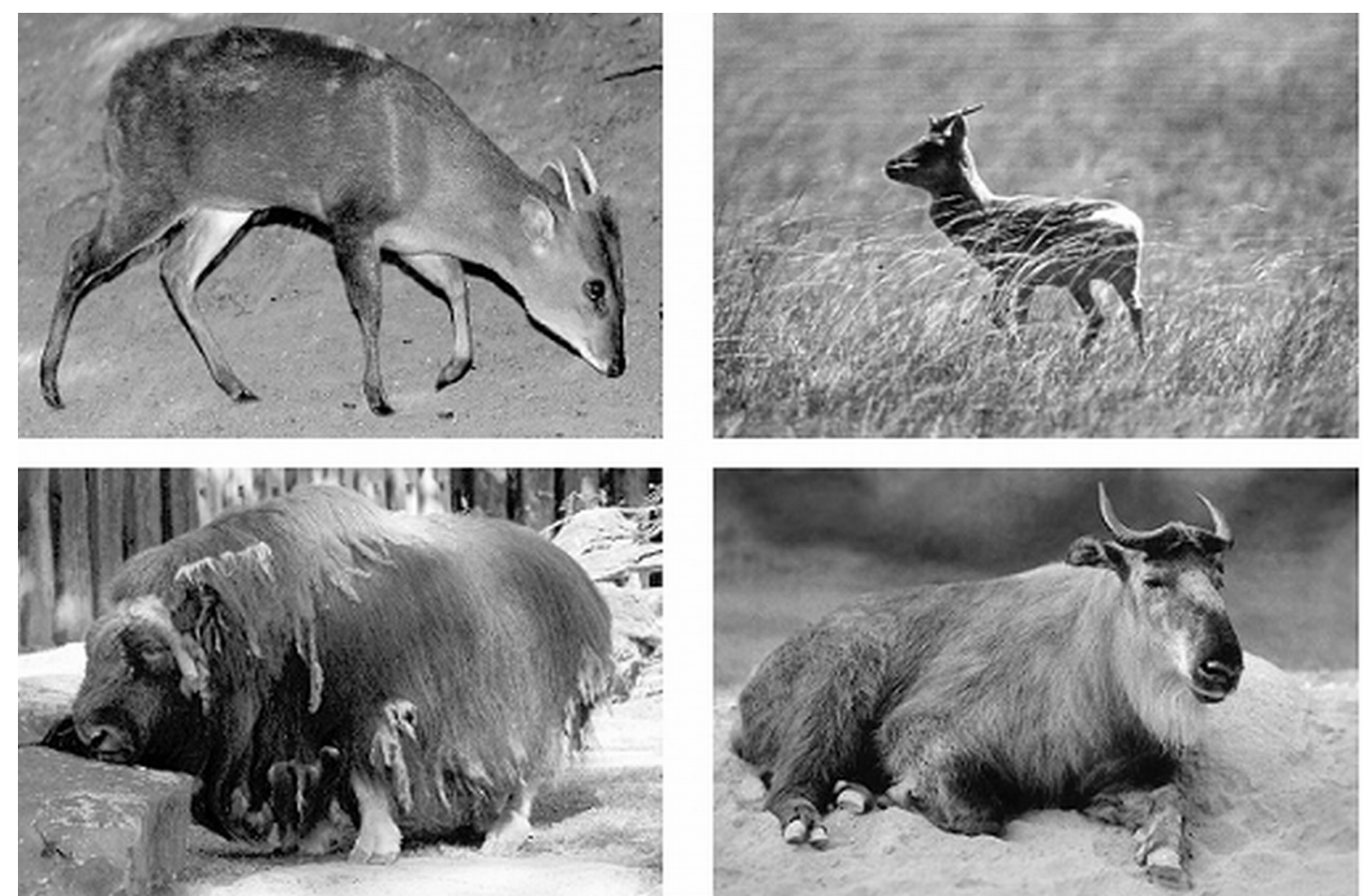

Figure 1: Investigated species (all males):

Muntiacus reevesi (top left), Procapra gutturosa (top right),

Budorcas taxicolor (below left) and Ovibos moschatus (below right)

(C) Zoo Köln (M. reevesi, O. moschatus), H. Mix (P. gutturosa), A. Michailov (B. taxicolor)

This contribution presents morphological studies of the vocal tract anatomy of the Chinese muntjac (Muntiacus reevesi), the Mongolian gazelle (Procapra gutturosa), the muskox (Ovibos moschatus), and the takin (Budorcas taxicolor). All of these species (Fig. 1) belong to the Artiodactyla, i.e. even-toed hoofed 
mammals. Vocalizations play an important role in the social systems of all four species. Practically, the investigation of the species was restricted by the difficulty of obtaining specimens and acoustic recordings of respective vocalizations.

Muntiacus reevesi is a small deer of approximately $15 \mathrm{~kg}$ body mass. M. reevesi is originally distributed in dense subtropical forests of Southern China and on the island of Taiwan. The individuals live mostly solitary and territorial. Normally, the home ranges of males exclude each other but include parts of the home ranges of several females. The mating system of M. reevesi is promiscuous and copulations can occur all over the year. Apart from acoustic communication, the olfactory communication plays an important role in the life of $M$. reevesi.

The body mass of Procapra gutturosa is approximately $30 \mathrm{~kg}$ in the male and $25 \mathrm{~kg}$ in the female. The habitats are open arid steppes and semi-desert regions in China, Mongolia and the Altai region of Russia. P. gutturosa is a nomadic species except during the rut. In the mating season dominant adult males occupy individual territories in which they retain several females, thus forming a harem. This behaviour is characteristic of a polygynous mating system.

The body mass of the arctic Ovibos moschatus is about $350 \mathrm{~kg}$ for adult males and one third less for females. Today, the animals inhabit the arctic tundras along the polar circle in the North of Canada and the North and Northeast of Greenland. The polygynous $O$. moschatus lives in mixed herds throughout most of the year. During the rut, a temporary harem-like association of females is formed and defended by a dominant male.

The male Budorcas taxicolor has a mean body mass of $300 \mathrm{~kg}$, the female of $200 \mathrm{~kg}$. Three subspecies are distributed in disjunctive mountain areas in Assam, Bhutan, Burma and China (including Tibet). The natural habitat of B. taxicolor ranges from grass covered alpine rocks to dense bamboo forests. In winter the animals live in small groups which unite to form larger herds during the summer months before the rut. Details of the mating system are unknown yet.

\section{Material and Methods}

The left halves of frozen heads and necks of Muntiacus reevesi, Ovibos moschatus, Budorcas taxicolor, and Procapra gutturosa were macroscopically dissected while the specimen were submerged in cold water. Consecutive dissection steps were documented by series of analogue photographic slides (Nikon F3) and also by digital images (Nikon CoolPix 950, Minolta DImage 7). Major stages were recorded in proportional drawings. The measurement of a string arranged along the vocal tract, i.e. from the vocal cleft to the upper lip, yielded the length of the vocal tract. 
In addition, heads of $M$. reevesi, of $O$. moschatus and of $P$. gutturosa were scanned by means of computer tomography (GE Lightspeed 4-Slice Spiral Computertomograph). Slice thickness was $0.6 \mathrm{~mm}$.

The vocalizations of $O$. moschatus and P. gutturosa were recorded be means of a DAT (digital audio tape) recorder (Sony TCD-D 100) and an appropriate directional monophonic microphone with wind cover (Sennheiser ME 80, including preamplifier $\mathrm{K} 3 \mathrm{U}$ ), whereas for the recordings of B.taxicolor the same recorder and a stereophonic microphone with overlapping kidney-shaped directionalities (Sony ECM-MS 907) were used. Additionally, we used earlier analogous audiotape recordings of $M$. reevesi made by unknown authors from a small herd formerly kept at the University of Bielefeld. Spectrograms were calculated by means of the program 'praat' (P. Boersma \& D. Weenink, University of Amsterdam, Netherlands; analysis width: $100 \mathrm{~ms}$, time steps: $10^{3}$, frequency steps: $10^{3}$, Gaussian window).

\section{Results and Discussion}

\subsection{The Chinese muntjac (Muntiacus reevesi)}

The larynx of $M$. reevesi may be taken as morphologically unspecialized (Fig. 2). It lacks any conspicuous enlargement of the laryngeal cartilages and any further specializations such as ventricles or air sacs. Significant differences between the larynges of both sexes of M. reevesi were not found. The membraneous vocal folds extend between the thyroid cartilage and the vocal process of the arytenoid cartilage. Thyroid and cricoid cartilage surround the laryngeal cavity.

The vocal repertoire of $M$. reevesi comprises miscellaneous types of calls from whimpers to barks with a broad overall frequency range. The best call type to demonstrate the filter impact of the vocal tract is the harmonic 'cheep' call (Fig. 3). Another call type is the noisy 'barking' which is used mainly as an alarm call. Only the latter can pass through the dense vegetation of M. reevesi's natural habitat for longer distances. 


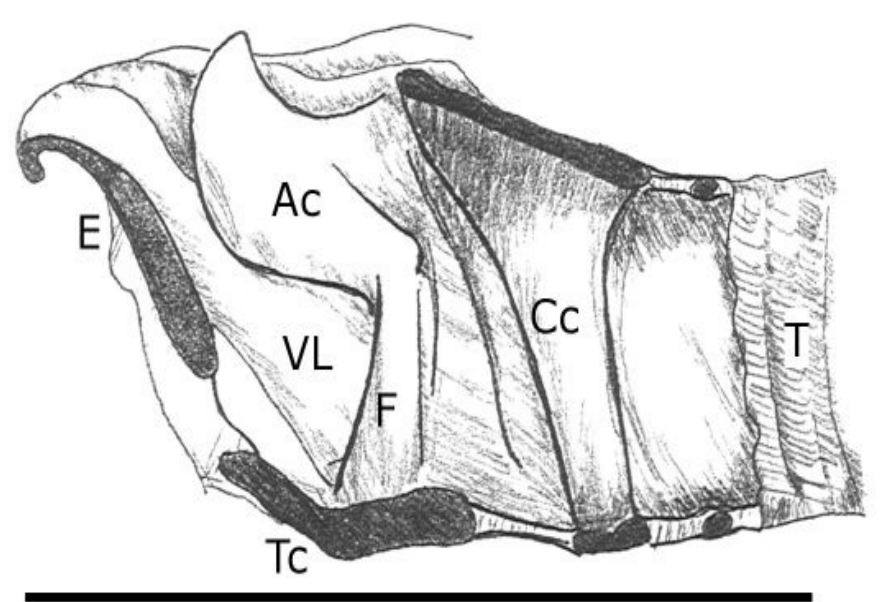

Figure 2: Larynx of Muntiacus reevesi Ac arytenoid cartilage, Cc cricoid cartilage, E epiglottis, $\mathrm{F}$ right vocal fold, $\mathrm{T}$ trachea, Tc thyroid cartilage, VL laryngeal vestibulum. Scale bar $=5 \mathrm{~cm}$.
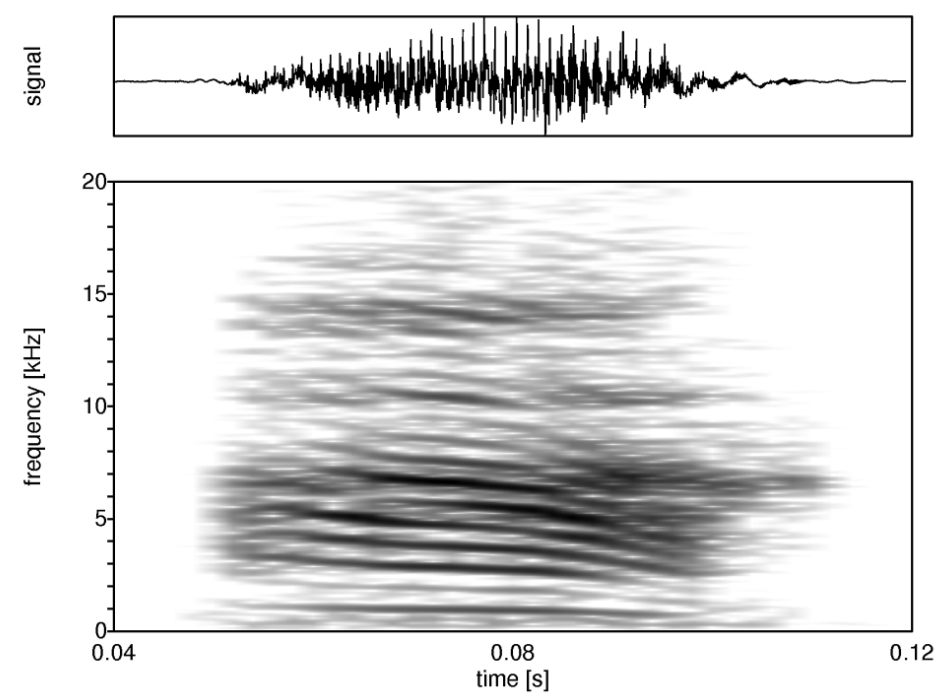

Figure 3: Narrow band spectrogram of Muntiacus reevesi's cheep call (adult, unknown sex)

\subsection{The Mongolian gazelle (Procapra gutturosa)}

In this species, sexual selection has led to a remarkable dimorphism of the larynx that is greater than expected by the differences of body masses. All cartilages of the male's larynx are enlarged. The thyroid bulges the ventral neck region (Fig. 4). 


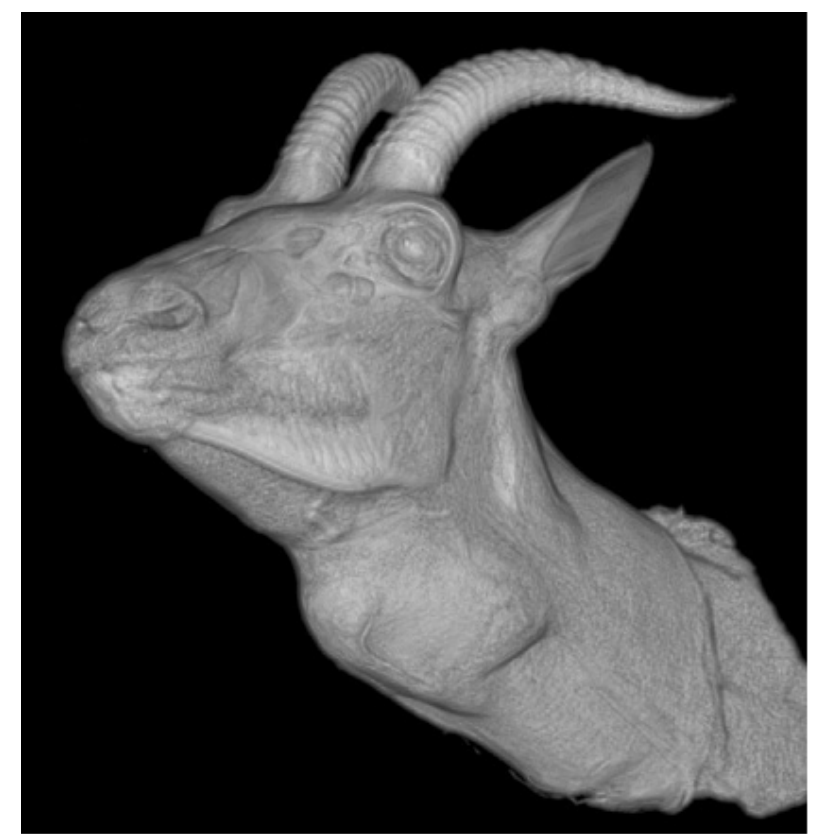

Figure 4: Head reconstruction of adult male

Procapra gutturosa without its hair coat, based on data from computer tomography

The arytenoid cartilages, together with the epiglottis, form an exceptionally large entrance to the larynx. Paired lateral ventricles are located between the arytenoid cartilage and the thyroarytenoid muscle. The vocal folds of the male P. gutturosa are supported by large fibroelastic pads (Fig. 5).

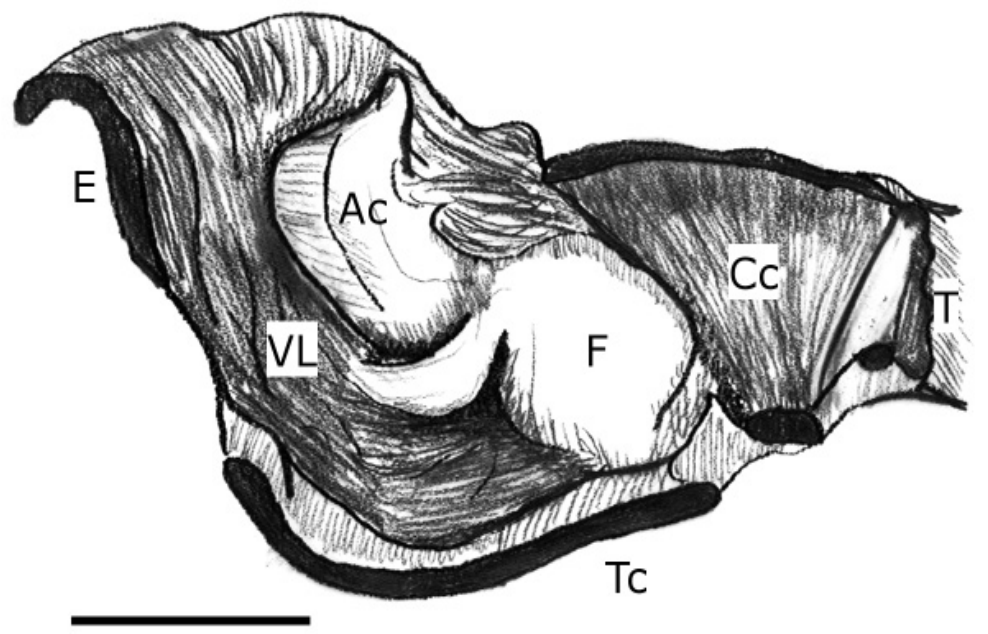

Figure 5: Larynx of Procapra gutturosa

Ac arytenoid cartilage, Cc cricoid cartilage, E epiglottis, $\mathrm{F}$ right vocal fold including fibroelastic pad, $\mathrm{T}$ trachea, Tc thyroid cartilage, VL laryngeal vestibulum.

Scale bar $=5 \mathrm{~cm}$.

Compared to the call of the female which has a fundamental frequency of about $600 \mathrm{~Hz}$, the specialized larynx of the male reduces the fundamental frequency 
by about $100 \mathrm{~Hz}$ (Fig. 6). In the open habitat of $P$. gutturosa a call with a lower pitch has a more homogeneous directivity. This may be an adaptation suited for multidirectional advertisement calls during the rut.
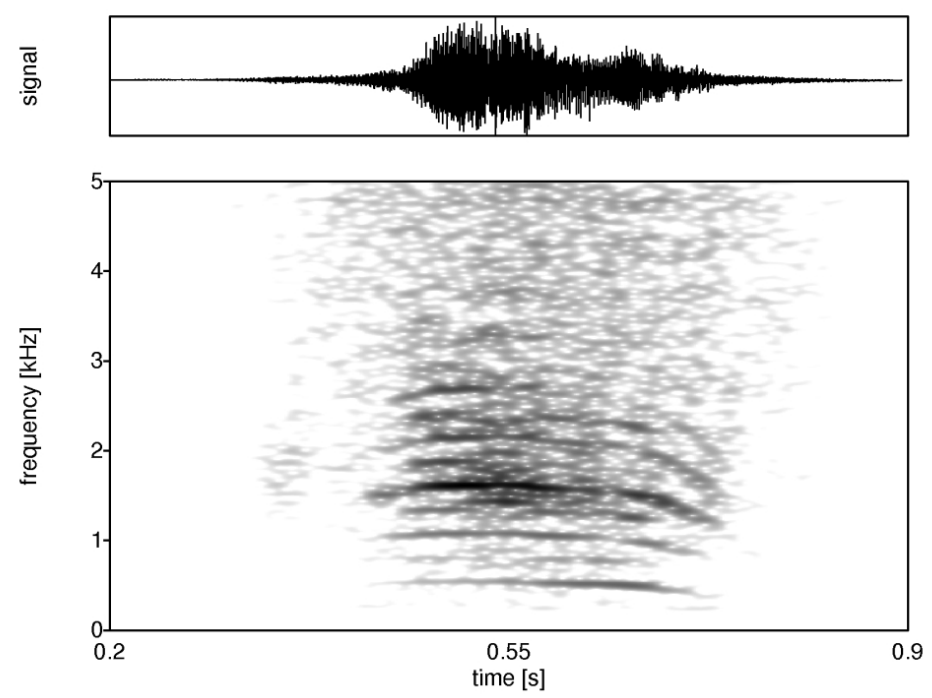

Figure 6: Narrow band spectrogram of a call of Procapra gutturosa with harmonic and subharmonic structures (adult male)

\subsection{The muskox (Ovibos moschatus)}

The male of $O$. moschatus has a small unpaired ventrorostral ventricle which extends into the extralaryngeal space (Fig. 7).

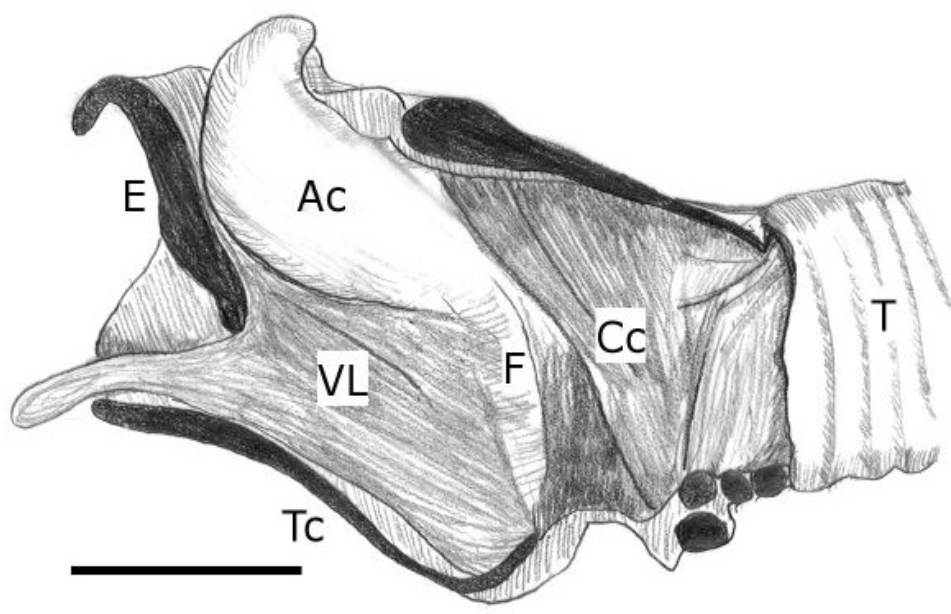

Figure 7: Larynx of a male Ovibos moschatus Ac arytenoid cartilage, Cc cricoid cartilage, E epiglottis, F right vocal fold, T trachea, Tc thyroid cartilage, VL laryngeal vestibulum. Scale bar $=5 \mathrm{~cm}$. 
This specialization may contribute to producing high amplitude calls with low fundamental frequencies. Both sexes achieve low frequencies of around $120 \mathrm{~Hz}$ (Fig. 8).
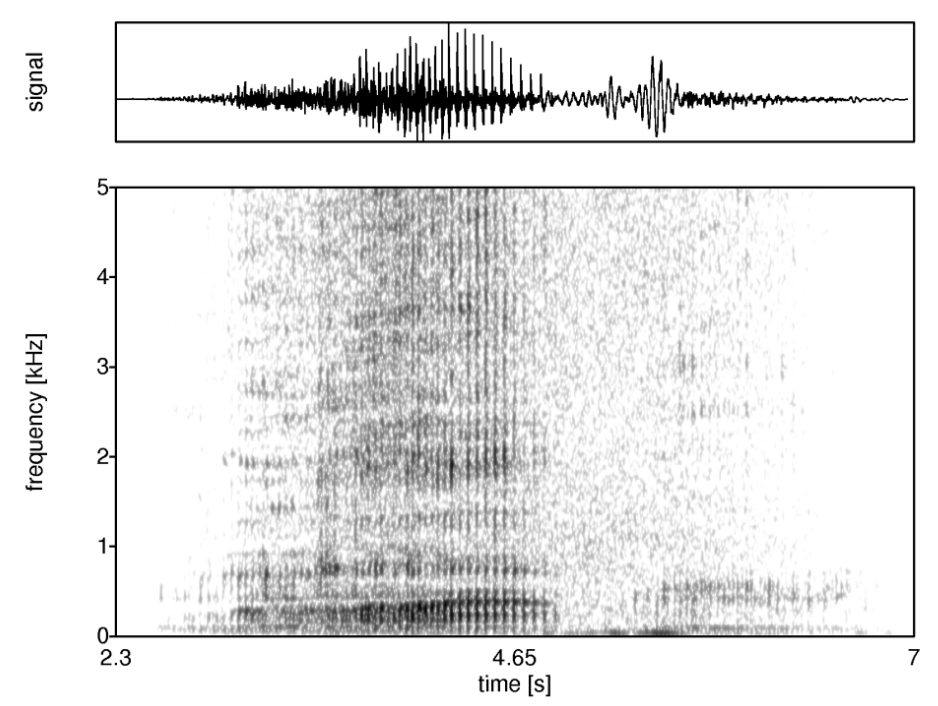

Figure 8: Narrow band spectrogram

of Ovibos moschatus's call with an additional pulse modulation (adult male)

Furthermore, the monotonous calls are characterized by their pulsed structure. The pulse rate averages $20 \mathrm{~Hz}$.

Low frequency parts in the glottal signal together with the ability to produce lower formants by vocal tract filtering might be important for the male's mating success within a polygynous mating system. For both sexes, low frequencies may be advantageous for the intra-group short-range communication under windy weather conditions predominating in their natural habitat.

\subsection{The takin (Budorcas taxicolor)}

Caudoventrally, the thyroid cartilage of both sexes of B.taxicolor forms a voluminous hollow structure (Fig. 9). This thyroid bulla is partially filled by extensions of the conspicuously enlarged vocal folds. As a consequence, the frequencies of vocalization decrease because of the mass increase of the vocal folds. This may be understood as an adaptation to communicate with conspecifics in a habitat covered with dense vegetation that attenuates higher frequencies. 


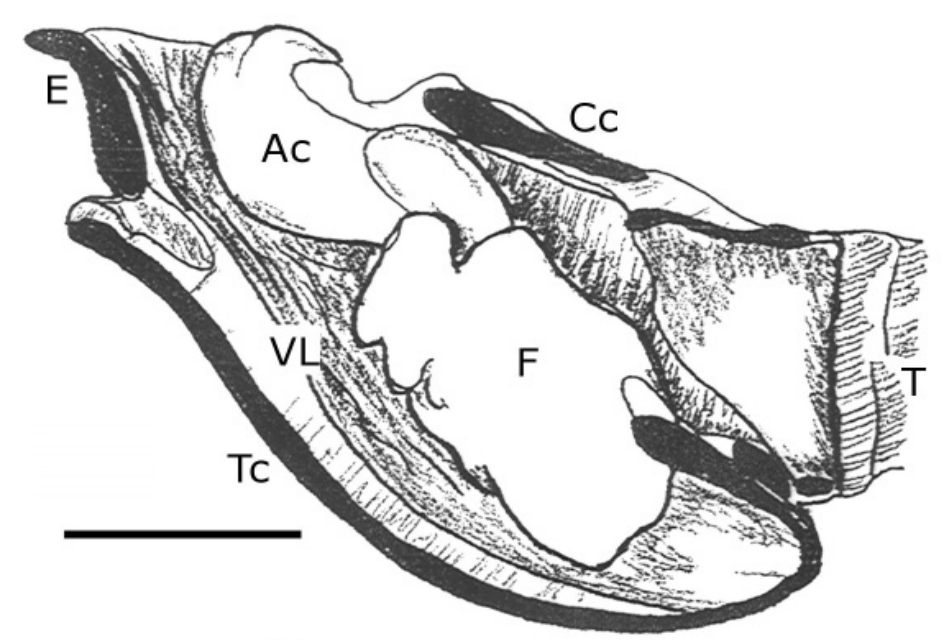

Figure 9: Larynx of Budorcas taxicolor

Ac arytenoid cartilage, Cc cricoid cartilage, E epiglottis, $\mathrm{F}$ enlarged right vocal fold, $\mathrm{T}$ trachea, Tc thyroid cartilage, VL laryngeal vestibulum. Scale bar $=5 \mathrm{~cm}$.

As in $O$. moschatus, the vocalization of B. taxicolor is also pulsed with a rate of about $20 \mathrm{~Hz}$ (Fig. 10). Lowest prominent frequencies are around $210 \mathrm{~Hz}$.
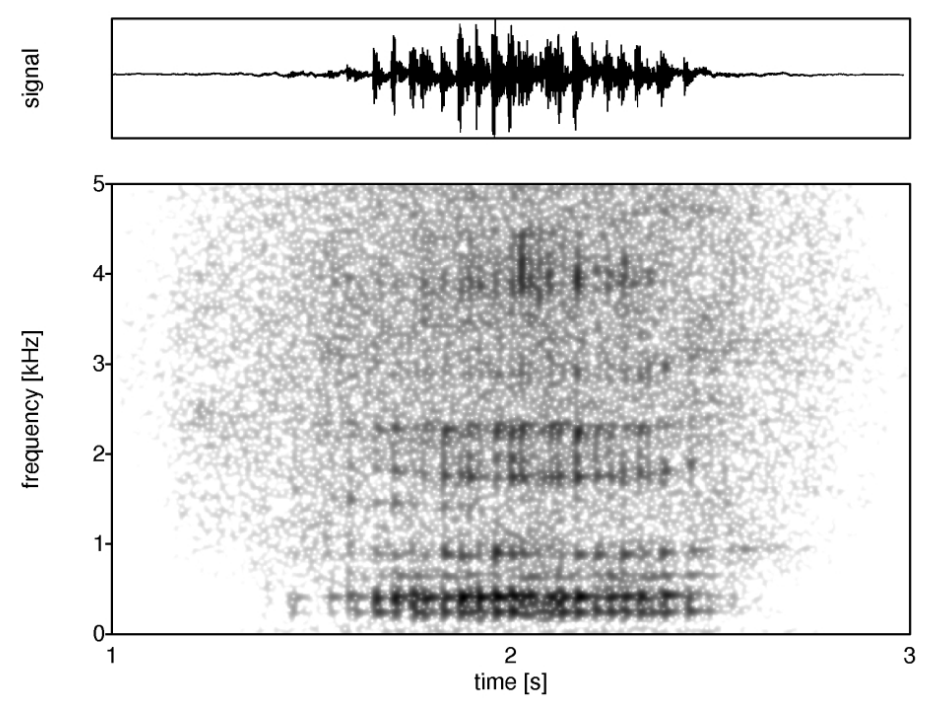

Figure 10: Narrow band spectrogram of a pulse modulated call of Budorcas taxicolor (adult male)

\section{Conclusions}

Tab. 1 summarizes the results. As the morphology of sound producing structures is a key to the interpretation of acoustic data, one species with less specialized and three species with more specialized larynges were investigated. In the latter three examples, the laryngeal characters vary in the following parameters: 
1. the lengths of the vocal folds

2. the masses of the vocal folds

3. the volume of the laryngeal air spaces,

i.e. the combined volumes of the laryngeal vestibulum and additional laryngeal ventricles

Evolutionary elongation and mass increase of the vocal folds led to a lowering of the fundamental frequency. The low frequency calls of the investigated species evolved as a consequence of, mainly, sexual (Procapra gutturosa) or natural (Budorcas taxicolor) selection, or both (Ovibos moschatus).

Table 1: Comparison between investigated species demonstrating differences of laryngeal anatomy, of fundamental frequencies, of acoustic properties of the natural habitats and of the mating systems

\begin{tabular}{|c|c|c|c|c|}
\hline Species & $\begin{array}{l}\text { Muntiacus } \\
\text { reevesi }\end{array}$ & $\begin{array}{l}\text { Procapra } \\
\text { gutturosa }\end{array}$ & $\begin{array}{l}\text { Ovibos } \\
\text { moschatus }\end{array}$ & $\begin{array}{l}\text { Budorcas } \\
\text { taxicolor }\end{array}$ \\
\hline $\begin{array}{l}\text { Sexual } \\
\text { dimorphism } \\
\text { of larynges }\end{array}$ & no & pronounced & $\begin{array}{l}\text { size } \\
\text { (proportional to } \\
\text { body mass?) }\end{array}$ & $\begin{array}{l}\text { size } \\
\text { (proportional to } \\
\text { body mass?) }\end{array}$ \\
\hline $\begin{array}{l}\text { Laryngeal } \\
\text { anatomy }\end{array}$ & $\begin{array}{l}\text { both sexes: } \\
\text { unspecialised }\end{array}$ & $\begin{array}{l}\text { male: } \\
\text { enlarged vocal } \\
\text { folds with } \\
\text { fibroelastic pads, } \\
\text { paired lateral } \\
\text { ventricles }\end{array}$ & $\begin{array}{l}\text { both sexes: } \\
\text { ventrorostral } \\
\text { ventricle, } \\
\text { enlarged } \\
\text { vestibulum }\end{array}$ & $\begin{array}{l}\text { both sexes: } \\
\text { large thyroid } \\
\text { bulla, } \\
\text { enlarged vocal } \\
\text { folds }\end{array}$ \\
\hline $\begin{array}{l}\text { Vocal tract } \\
\text { length } \\
\text { (male/female) } \\
\text { [mm] }\end{array}$ & $130 / 140$ & $370 / ?$ & $470 / ?$ & $470 / ?$ \\
\hline $\begin{array}{l}\text { Fundamental } \\
\text { frequency } \mathbf{f}_{0} \\
\text { (male/female) } \\
{[\mathrm{Hz}]}\end{array}$ & $1000 / 1000$ & $500 / 600$ & $90 / 95$ & $210 / 210$ \\
\hline $\begin{array}{l}\text { Acoustic } \\
\text { properties } \\
\text { of habitat }\end{array}$ & $\begin{array}{l}\text { attenuation } \\
\text { of most call } \\
\text { frequencies }\end{array}$ & $\begin{array}{l}\text { attenuation } \\
\text { of higher call } \\
\text { frequencies }\end{array}$ & $\begin{array}{l}\text { unknown } \\
\text { (long distance } \\
\text { communication } \\
\text { might be not } \\
\text { important) }\end{array}$ & $\begin{array}{l}\text { attenuation } \\
\text { of higher call } \\
\text { frequencies }\end{array}$ \\
\hline Mating system & promiscuous & polygynous & polygynous & unknown \\
\hline
\end{tabular}

Although laryngeal ventricles were evolved independently in several taxonomic groups, their function is still unclear. Laryngeal ventricles might act as additional resonator devices which modify the acoustic filter function of the 
upper respiratory tract. Supporting evidence comes from the investigation of the human piriform recess (Dang \& Honda 1997).

\section{References}

Boe, L.J., Heim, J.L., Honda, K. and Maeda, S. (2002): The potential Neanderthal vowel space was as large as that of modern humans. Journal of Phonetics 30: 465-484.

Dang, J. \& Honda, K. (1997): Acoustic characteristics of the piriform fossa in models and humans. Journal of the Acoustic Society of America 101 (1): 456-465.

Fitch, T. \& Reby, D. (2001): The descended larynx is not uniquely human. Proceedings of the Royal Society B 268: 1669-1675.

Frey, R. \& Gebler, A. (2003): The highly specialized vocal tract of the male Mongolian gazelle (Procapra gutturosa Pallas, 1777 - Mammalia, Bovidae). Journal of Anatomy 203: 451-471.

Frey, R., Gebler, A. \& Fritsch, G. (2005): Arctic roars - laryngeal anatomy and vocalization of the muskox (Ovibos moschatus Zimmermann, 1780, Bovidae). Journal of Zoology (accepted)

Frey, R. \& Hofmann, R.R. (2000): Larynx and vocalization of the Takin (Budorcas taxicolor Hodgson, 1850 - Mammalia, Bovidae). Zoologischer Anzeiger 239: 197-214.

Gebler, A. (2003): The Vocal Tract Anatomy of the Chinese Muntjac (Muntiacus reevesi Ogilby, 1839). Proceedings of the First International Conference on Acoustic Communication by Animals, College Park, Maryland: 93.

Lieberman, P. \& Crelin, E. S. (1971): On the speech of Neanderthal man. Linguistic Inquiry 2: 203-222.

Nishimura, T., Mikami, A., Suzuki, J. \& Matsuzawa, T. (2003): Descent of the larynx in chimpanzee infants. Proceedings of the National Academy of Science of the United Nations of America 100 (12): 6930-6933. 